\title{
Expressed emotion varies with eating disorder diagnosis
}

By Dr Jessica K. Edwards

Unique patterns of expressed emotion characterize communication within families with children affected by eating disorders, according to new research. Researchers across the USA recruited 215 adolescents (aged 12-19 years) with eating disorders and their families, and asked them to complete the Standardized Clinical Family Interview. Levels of expressed emotion were then scored by trained raters who watched recorded videos of the interviews. They found that fathers made more critical comments to children with bulimia nervosa or major depressive disorder than to those with anorexia nervosa. Mothers also made more critical comments towards children with bulimia nervosa and made the least number of positive remarks to those with major depressive disorder. Overall, fathers in intact households showed more warmth and made less critical comments than those in non-intact households. Mothers from intact households made fewer critical comments, but also made fewer positive remarks than mothers in non-intact households. The presence of a sibling in the family reduced the mother's warmth and emotional over-involvement. The researchers consider that therapists should assess for parental expressed emotion and initiate interventions to reduce high levels of expressed emotion where possible.

Rienecke, R.D., Sim, L., Lock, J. \& Le Grange, D. (2016), Patterns of expressed emotion in adolescent eating disorders. J Child Psychol Psychiatr. 57: 1407-1413. doi:10.1111/jcpp.12594

\section{Glossary:}

Expressed emotion: a measure of critical, hostile and emotionally over-involved attitude that relatives have towards family members with a disorder

Intact household: a family in which there has been no dissolution of marriage through death or divorce

Non-intact household: a family in which some type of dissolution of marriage has occurred 